\title{
Genetic characteristics of non-familial epilepsy
}

\author{
Kyung-Wook Kang ${ }^{1}$, Wonkuk Kim ${ }^{2}$, Yong Won Cho ${ }^{3}$, Sang Kun Lee ${ }^{4}$, Ki-Young Jung ${ }^{4}$, Won Chul Shin ${ }^{5}$, Dong \\ Wook Kim ${ }^{6}$, Won-Joo Kim ${ }^{7}$, Hyang Woon Lee ${ }^{8}$, Woojun Kim ${ }^{9}$, Keun Tae Kim ${ }^{3}$, So-Hyun Lee ${ }^{10}$, Seok-Yong Choi \\ Corresp., 10 , Myeong-Kyu Kim ${ }^{\text {Corresp. } 1}$ \\ 1 Department of Neurology, Chonnam National University Medical School, Gwangju, South Korea \\ 2 Department of Applied Statistics, Chung-Ang University, Seoul, South Korea \\ 3 Department of Neurology, Keimyung University Dongsan Medical Center, Daegu, South Korea \\ 4 Department of Neurology, Seoul National University Hospital, Seoul, South Korea \\ 5 Department of Neurology, Kyung Hee University Hospital at Gangdong, Seoul, South Korea \\ 6 Department of Neurology, Konkuk University School of Medicine, Seoul, South Korea \\ 7 Department of Neurology, Gangnam Severance Hospital, Yonsei University College of Medicine, Seoul, South Korea \\ 8 Department of Neurology, Ewha Womans University School of Medicine and Ewha Medical Research Institute, Seoul, South Korea \\ 9 Department of Neurology, Seoul St. Mary's Hospital, College of Medicine, The Catholic University of Korea, Seoul, South Korea \\ 10 Department of Biomedical Science, Chonnam National University Medical School, Gwangju, South Korea \\ Corresponding Authors: Seok-Yong Choi, Myeong-Kyu Kim \\ Email address: zebrafish@jnu.ac.kr, mkkim@jnu.ac.kr
}

Background . Knowledge of the genetic etiology of epilepsy can provide essential prognostic information and influence decisions regarding treatment and management, leading us into the era of precision medicine. However, the genetic basis underlying epileptogenesis or epilepsy pharmacoresistance is not well-understood, particularly in nonfamilial epilepsies with heterogeneous phenotypes that last until or start in adulthood.

Methods. We sought to determine the contribution of known epilepsy-associated genes to the causation of non-familial epilepsies with heterogeneous phenotypes and to the genetic basis underlying epilepsy pharmacoresistance. We performed a multi-center study for whole exome sequencing-based screening of 178 selected epilepsy-associated genes in 243 non-familial adult patients with primarily focal epilepsy (122 drug-resistant and 121 drug-responsive epilepsies). The pathogenicity of each variant was assessed through a customized stringent filtering process and classified according to the American College of Medical Genetics and Genomics guidelines. Results. Possible causal genetic variants of epilepsy were uncovered in $13.2 \%$ of non-familial patients with primarily focal epilepsy. The diagnostic yield according to the seizure onset age was $25 \%(2 / 8)$ in the neonatal and infantile period, $11.1 \%(14 / 126)$ in childhood, and $14.7 \%(16 / 109)$ in adulthood. The higher diagnostic yields were from ion channel-related genes and mTOR pathway-related genes, which does not significantly differ from the results of previous studies on familial or earlyonset epilepsies. These potentially pathogenic variants, which were identified in genes that 
have been mainly associated with early-onset epilepsies with severe phenotypes, were also linked to epilepsies that start in or last until adulthood in this study. This finding suggested the presence of one or more disease-modifying factors that regulate the onset time or severity of epileptogenesis. The target hypothesis of epilepsy pharmacoresistance was not verified in our study. Instead, neurodevelopment-associated epilepsy genes, such as TSC2 or RELN, or structural brain lesions were more strongly associated with epilepsy pharmacoresistance. Conclusions. We revealed a fraction of possible causal genetic variants of non-familial epilepsies in which genetic testing is usually overlooked. In this study, we highlight the importance of earlier identification of the genetic etiology of nonfamilial epilepsies, which leads us to the best treatment options in terms of precision medicine and to future neurobiological research for novel drug development. This should be considered a justification for physicians determining the hidden genetics of non-familial epilepsies that last until or start in adulthood. 
1

2

3

4

5

6

\section{Genetic characteristics of non-familial epilepsy}

Kyung-Wook Kang ${ }^{1}$, Wonkuk Kim², Yong Won $\mathrm{Cho}^{3}$, Sang Kun Lee ${ }^{4}$, Ki-Young Jung ${ }^{4}$, Won Chul Shin ${ }^{5}$, Dong Wook Kim ${ }^{6}$, Won-Joo Kim ${ }^{7}$, Hyang Woon Lee ${ }^{8}$, Woojun Kim9, Keun Tae Kim ${ }^{3}$, So-Hyun Lee ${ }^{10}$, Seok-Yong Choi ${ }^{10^{*}}$, Myeong-Kyu Kim ${ }^{1^{*}}$

${ }^{1}$ Department of Neurology, Chonnam National University Hospital, Gwangju, 61469, South Korea

${ }^{2}$ Department of Applied Statistics, Chung-Ang University, Seoul, 06974, South Korea

${ }^{3}$ Department of Neurology, Keimyung University Dongsan Medical Center, Daegu, 41931, South Korea

${ }^{4}$ Department of Neurology, Seoul National University Hospital, Seoul, 03080, South Korea

${ }^{5}$ Department of Neurology, Kyung Hee University Hospital at Gangdong, Seoul, 05278, South Korea

${ }^{6}$ Department of Neurology, Konkuk University School of Medicine, Seoul, 05030, South Korea

${ }^{7}$ Department of Neurology, Gangnam Severance Hospital, Yonsei University College of Medicine, Seoul, 06273, South Korea.

${ }^{8}$ Departments of Neurology, Ewha Womans University School of Medicine and Ewha Medical Research Institute, Seoul, 07985, South Korea

${ }^{9}$ Department of Neurology, Seoul St. Mary's Hospital, College of Medicine, The Catholic University of Korea, Seoul, 06591, South Korea

${ }^{10}$ Department of Biomedical Sciences, Chonnam National University Medical School, Gwangju, 61469, South Korea.

\section{* Corresponding authors;}

\section{Myeong-Kyu Kim}

Department of Neurology, Chonnam National University Hospital, Gwangju, 61469, South Korea

Email address: $\underline{\text { mkkim@jnu.ac.kr }}$

\section{Seok-Yong Choi}

Department of Biomedical Sciences, Chonnam National University Medical School, Gwangju, 61469, South Korea. Email address: zebrafish@,jnu.ac.kr 
Background. Knowledge of the genetic etiology of epilepsy can provide essential

prognostic information and influence decisions regarding treatment and management, leading us into the era of precision medicine. However, the genetic basis underlying epileptogenesis or epilepsy pharmacoresistance is not well-understood, particularly in non-familial epilepsies with heterogeneous phenotypes that last until or start in adulthood.

Methods. We sought to determine the contribution of known epilepsy-associated genes to the causation of non-familial epilepsies with heterogeneous phenotypes and to the genetic basis underlying epilepsy pharmacoresistance. We performed a multi-center study for whole exome sequencing-based screening of 178 selected epilepsy-associated genes in 243 non-familial adult patients with primarily focal epilepsy (122 drug-resistant and 121 drug-responsive epilepsies). The pathogenicity of each variant was assessed through a customized stringent filtering process and classified according to the American College of Medical Genetics and Genomics guidelines. $14.7 \%(16 / 109)$ in adulthood. The higher diagnostic yields were from ion channel-related genes and mTOR pathway-related genes, which does not significantly differ from the results of previous studies on familial or early-onset epilepsies. These potentially pathogenic variants,

51 which were identified in genes that have been mainly associated with early-onset epilepsies with severe phenotypes, were also linked to epilepsies that start in or last until adulthood in this study. 
53 This finding suggested the presence of one or more disease-modifying factors that regulate the

54 onset time or severity of epileptogenesis. The target hypothesis of epilepsy pharmacoresistance

55 was not verified in our study. Instead, neurodevelopment-associated epilepsy genes, such as

$56 T S C 2$ or RELN, or structural brain lesions were more strongly associated with epilepsy

57 pharmacoresistance.

Conclusions. We revealed a fraction of possible causal genetic variants of non-familial

59 epilepsies in which genetic testing is usually overlooked. In this study, we highlight the

60

61

62

63

64

65

66

67

68

69 importance of earlier identification of the genetic etiology of non-familial epilepsies, which leads us to the best treatment options in terms of precision medicine and to future neurobiological research for novel drug development. This should be considered a justification for physicians determining the hidden genetics of non-familial epilepsies that last until or start in adulthood. 
71

72

73

74

Epilepsy is one of the most common neurological conditions affecting approximately 8 of every 1,000 individuals worldwide (Fiest et al., 2017). Although its detailed pathogenesis remains largely unknown, a cumulative understanding of the genetic basis of epilepsy revealed that many epilepsies that were previously considered idiopathic should be reclassified as having a genetic cause (Thomas \& Berkovic, 2014). Even acquired epilepsies resulting from trauma, stroke, neoplasm, infection, or congenital malformation are now known to be associated with genetic contributions (Thomas \& Berkovic, 2014). Indeed, hundreds of genes have already been associated with epilepsy to date (Wang et al., 2017), and have now been incorporated into commercial clinical tests with comprehensive gene panels for the rapid identification of causative genetic mutations of many forms of epilepsy (Møller et al., 2016; Hildebrand et al., 2016; Dunn et al., 2018). This is highly important, because knowledge of the genetic etiology can provide essential prognostic information and influence decisions regarding treatment and management, leading us into the era of precision medicine (Milligan et al., 2014; Pierson et al., 2014; Lindy et al., 2018).

Unlike neonatal- and childhood-onset epilepsy, in which both availability of genetic testing and the actionability of test results are higher (Møller et al., 2016), enquiry into genetic causes of epilepsy has been overlooked in adult patients with epilepsy (APEs) for a number of reasons (Thomas \& Berkovic, 2014): underappreciation of the role of genetic factors in certain epilepsies such as adult-onset focal epilepsy, an inexact causal attribution such as mistakenly ascribing a developmental epileptic encephalopathy (DEE) to birth trauma and, not least, unknown family history resulting from the absence of the oldest living relative who tends to be the most accurate custodian of family history or excessive social stigma leading to non-disclosure of seizures in the 
93 patient's older relatives. It is also notable that most non-familial APEs in practice are not willing

94 to submit their unaffected family members to genetic testing, resulting in the inheritance pattern

95 of the family often being inconclusive. Furthermore, in most APEs, particularly those who are

96 not candidates for presurgical evaluations, either voluntarily or involuntarily, the detailed

97 epilepsy phenotypes are generally indistinct. All of these factors have contributed to reluctance

98 in genetic testing of APEs in practice, delaying our understanding of the genetic basis of non-

99 familial epilepsies and preventing APEs from having the opportunity to receive potentially better

100 treatment options.

101 However, the paradigm of genetically diagnosing non-familial APEs has shifted with

102 advances in sequencing technology. It is now well-known that genetic diagnosis is no longer an

103 exclusive property of certain familial Mendelian epilepsies. For example, post-zygotic de novo

104 mutations have been discovered in some sporadic focal epilepsies or DEEs, thus indicating

105 genetic causation in patients with epilepsy even without a family history (Phillips et al., 2000;

106 Claes et al., 2001; Bisulli et al., 2004; Nava et al., 2014). Furthermore, this paradigm shift

107 provides us with optimistic but reasonable prospects. There might be undetermined causal

108 variants in non-familial APEs, particularly those experiencing earlier onset of seizures, as their

109 epilepsy diagnosis was likely made in the non-genomic era when adequate genetic testing was

110 not available, and as such were not genetically diagnosed. In addition, there might be a hidden

111 native genetic basis of non-familial adult-onset epilepsy, as suggested by surprising genetic

112 causes in pediatric patients with non-familial DEEs (Claes et al., 2001; Nava et al., 2014).

113 The higher diagnostic yield of genetic testing in DEEs has been associated with primarily

114 drug-refractory seizures (Møller et al., 2016; Ko et al., 2018; Rim et al., 2018), which indicates

115 that causal genes of DEEs could be linked to pharmacoresistance. Indeed, the target hypothesis is 
116 one of the most frequently cited theories of epilepsy pharmacoresistance, and postulates that

117 alterations in the properties of antiepileptic drug (AED) targets, such as compositional changes in

118 voltage-gated ion channels and neurotransmitter receptors, result in decreased drug sensitivity

119 and thus leads to refractoriness (Tang, Hartz \& Bauer, 2017). Interestingly, the genes encoding

120 the voltage-gated ion channels and neurotransmitter receptors have also been most commonly

121 associated with epilepsy (Wang et al., 2017; Lindy et al., 2018). This indicates that there might

122 be a common pathway underlying both epileptogenesis and epilepsy pharmacoresistance.

123 In the present study, we sought to determine the contribution of known epilepsy-associated genes (EAGs) to the causation of non-familial epilepsies with heterogeneous phenotypes and to the genetic basis underlying epilepsy pharmacoresistance.

\section{Materials and Methods}

\section{Study design and participants}

130 In this multi-center study, consecutive patients with an established clinical diagnosis of

131 epilepsy as defined by a practical clinical definition of epilepsy (Fisher et al., 2014) and who had

132 been managed by epilepsy specialists over a period of 2 years were recruited from 10 tertiary

133 epilepsy referral centers in Korea. All study participants were eligible if they had drug-resistant

134 (DR group) or drug-responsive (DS group) epilepsy according to the following definitions and

135 criteria. To enhance the contrast of phenotype between DS and DR group, we defined drug

136 resistance more stringently than the conventional definition (Kwan et al., 2010) as the occurrence 
137 of at least 12 unprovoked seizures over the course of 1 year before recruitment, with trials of 2 or

138 more appropriate AEDs at the maximal tolerated doses, which were established on the basis of

139 the occurrence of clinical side effects at supramaximal doses. Patients who underwent surgical

140 treatment for drug-resistant epilepsy were classified as having drug-resistant epilepsy, regardless

141 of the surgical outcome. In patients treated with a single AED, drug responsiveness was defined

142 as complete freedom from seizures for at least 1 year up to the date of the last follow-up visit.

143 However, patients who had a definite history of epilepsy in first- or second-degree relatives,

144 were frequently in poor compliance with AED therapy, had reported non-motor seizures only

145 without consciousness impairment, or had progressive DEEs were excluded.

146 An extensive historical assessment was performed in all participants using a standardized

147 form, detailing the epidemiology, seizure characteristics, epilepsy syndrome,

148 electroencephalography and magnetic resonance imaging findings, family history, treatment, and

149 treatment-emergent adverse events.

150 This study was approved by the institutional review boards at Chonnam National University

151 Hospital (CNUH-20160028). All research was performed in accordance with relevant guidelines

152 and regulations, and written informed consent was obtained from all study participants.

\section{Whole exome sequencing}

Following genomic DNA (gDNA) extraction from whole blood, the Agilent SureSelect

156 Target Enrichment protocol for Illumina paired-end sequencing (ver. B.3, June 2015; Agilent

157 Technologies, Santa Clara, CA) was used together with 200 ng input gDNA for the generation of 158 standard exome capture libraries. In all cases, the SureSelect Human All Exon V5 probe set was used. For exome capture, 250 ng of DNA library was mixed with hybridization buffers, blocking 
160 mixes, RNase inhibitors, and $5 \mu 1$ of the SureSelect all exon capture library, according to the

161 standard Agilent SureSelect Target Enrichment protocol. Hybridization to the capture baits was

162 conducted at $65^{\circ} \mathrm{C}$ using the heated thermal cycler lid option at $105^{\circ} \mathrm{C}$ for $24 \mathrm{~h}$ on a polymerase

163 chain reaction (PCR) machine. The captured DNA was amplified, purified, quantified, and then

164 sequenced using the HiSeq ${ }^{\mathrm{TM}} 2500$ platform (Illumina, San Diego, USA). For sequence

165 alignment, paired-end sequences were first mapped to the human genome (UCSC assembly hg19;

166 original GRCh37 from NCBI, Feb. 2009) using BWA (Burrows-Wheeler Alignment Tool,

167 v0.7.12). The programs packaged in PicardTools (v1.130, Broad Institute, Cambridge, MA) were

168 then applied to remove PCR duplicates. Base quality score recalibration and local realignment

169 around indels were performed using the Genome Analysis Toolkit (GATK; Broad Institute) to

170 locally realign reads such that the number of mismatching bases was minimized across all reads.

171 Based on the previously generated binary alignment map file, variant genotyping for each sample

172 was performed using the Haplotype Caller in the GATK. Those variants are annotated by another

173 program called SnpEff (v4.1g, http://snpeff.sourceforge.net/), converted to the vcf file format,

174 filtered through the single nucleotide polymorphism (SNP) database (dbSNP, v142), and

175 compared to SNPs from the 1000 Genome Projects. Our in-house program and SnpEff were then

176 applied to filter the data through additional databases, including ESP6500, ClinVar, and

177 dbNSFP2.9.

179 Whole exome sequencing interpretation

180 The workflow for whole exome sequencing (WES) data interpretation to identify high confidence candidate variants with higher predicted potential for pathogenicity in epilepsy is

182 provided in Figure 1. Briefly, variants satisfying all of the following conditions were further 
183 analyzed: variants with a read depth of $>30 \mathrm{x}$, variants predicted to be disruptive or damaging to

184 the protein for which they code (frame-shifted, nonsense, non-synonymous missense, small

185 indels, or canonical splice site variants), and variants of 178 known EAGs (Table 1). The

186 selection criteria of the EAGs were as follows: 1) epilepsy genes that cause pure or relatively

187 pure epilepsies or syndromes with epilepsy as the core symptom $(n=105)$, and 2$)$

188 neurodevelopment-associated epilepsy genes that produce gross neurodevelopmental

189 malformation and epilepsy $(\mathrm{n}=73)$, which may vary in severity (Perucca et al., 2017; Wang et al., 190 2017).

191 Of the selected variants, variants with a minor-allele frequency of $>1 \%$ in the Korean

192 Reference Genome Database (KRGDB; http://152.99.75.168/KRGDB/) or Exome Aggregation

193 Consortium (ExAC; http://exac.broadinstitute.org/) were excluded from further analysis, as an

194 allele frequency in a control population that is greater than expected for the disorder is

195 considered strong support for a benign interpretation (Richards et al., 2015).

196 The deleteriousness of the selected variants was predicted by 11 current deleteriousness-

197 scoring methods, including 8 function prediction methods (Polyphen-2_HDIV, Polyphen-

198 2_HVAR, SIFT, MutationTaster, Mutation Assessor, LRT, FATHMN, and PROVEAN), 1

199 conservation score method (GERP++), and 2 ensemble score methods (MetaSVM and MetaLR).

200 The variants predicted by two or more prediction scores as deleterious or damaging to the protein

201 for which they code were included in further analysis. The pairs of prediction scores, Polyphen-

202 2_HDIV and Polyphen-2_HVAR, and MetaSVM and MetaLR, received a single score each in

203 the scoring of the deleteriousness of a variant because the two prediction scores in each pair have

204 a strong linear correlation (Dong et al., 2015; Xiaoming et al., 2016). Known pathogenic variants

205 or synonymous variants causing the same amino acid change were determined by searching 
206 ClinVar (https://www.ncbi.nlm.nih.gov/clinvar/) and the latest professional version of the

207 Human Gene Mutation Database (http://www.hgmd.cf.ac.uk/). Any inconsistency among the

208 sources was considered as uncertain in the functional significance of the variants.

209 The final variants selected via the filtering steps were classified using a five-class scheme of

210 pathogenicity (pathogenic, likely pathogenic, uncertain significance, benign, or likely benign)

211 according to the latest guidelines for the interpretation of sequence variants by the American

212 College of Medical Genetics and Genomics (ACMG) (Richards et al., 2015). Among the variants

213 classified as pathogenic or likely pathogenic (P/LPs), a heterozygous variant alone in exclusively

214 recessive genes presenting as a typical recessive disorder was tested for compound

215 heterozygosity using CNVkit (Talevich et al., 2016) for copy number detection. All variants

216 selected as P/LPs were validated by Sanger sequencing.

217

\section{Statistics}

Of the approximately 600 APEs that were consecutively enrolled in this study, age- and gender-matched APEs were randomly assigned to the DR and DS groups. The two groups were compared by Fisher's exact test for categorical data or Student's $t$-test for continuous data. A $p$ value of $<0.05$ was considered significant. The Statistical Package for the Social Sciences (v23.0; SPSS, Chicago, IL) was used for all analyses. significantly increased compared to the control group, the odds ratio (OR) of each variant was calculated using the adjusted allele frequency of the variant in the ExAC database. If the OR was

$227>5.0$ and the confidence interval (CI) around the estimate of the OR did not include 1.0, the difference in prevalence between the groups was considered to be statistically significant 
229 (Richards et al., 2015).

230

231

232 Results

233

\section{Participant characteristics}

A total of 243 APEs (121 in the DS group and 122 in the DR group) were randomized and 236

their epidemiological and clinical characteristics are provided in Table 2. Briefly, the mean ages

at recruitment and at seizure onset were approximately 40 (median; 38, range; 20 84) and 20

(median; 17, range; 0 68) years, respectively. According to the seizure onset age, 3.3\% (8/243)

239

experienced their first seizure in the neonatal and infantile period (aged 0-1 year), 51.9\% $(126 / 243)$ in childhood (aged 2-18 years), and 44.9\% (109/243) in adulthood (aged >19 years).

The mean age at seizure onset was significantly different between the DS and DR groups, but was similar between APEs with and without P/LPs (21.1 \pm 14.4 and $20.6 \pm 13.7$ years, 243 respectively).

\section{Identification of pathogenic variants}

All participants underwent high-coverage WES and yielded a total of 532,403 variants from which, after a customized stringent six-step filtering process (Figure 1), 26 variants in 15 EAGs were determined to be P/LPs (3 pathogenic and 23 likely pathogenic) according to the ACMG guideline (Richards et al., 2015) in 32 of 243 APEs (13.2\%) (Table 3). The diagnostic yield according to seizure onset age was $25 \%(2 / 8)$ in the neonatal and infantile period, $11.1 \%(14 / 126)$ 
251 in childhood, and 14.7\% (16/109) in adulthood (Table 4).

252 Three of the twenty-six P/LPs identified in this study were novel variants (absent from 253 controls in the ExAC database), and the remaining twenty-three P/LPs were known but

254 extremely rare variants of which the mean OR was 85.5 (range; 7.02-376.9) and the CI around

255 each estimate of the OR did not include 1. The classification criteria for the pathogenicity of

256 each P/LP applied according to the ACMG guideline in this study are described in Table 3.

257 Thirty heterozygous variants classified as P/LPs of nineteen recessive genes (ALDHDA1, ASPM, 258 CCDC88C, CENPJ, CLN3, CLN8, GPR56, LAMB1, MECP2, MFSD8, NHLRC1, NRXN1, 259 POLG, RTTN, SLC12A6, TBC1D24, TRMT10A, TUBA8, and WWOX) were not included in the 260 diagnostic yield calculation.

261

\section{Presumed disease-causative genes of non-familial epilepsies} variants of mTOR pathway-related genes (DEPDC5 p.Arg587* and TSC2 p.Glu1476Gln).

Among the 23 variants classified as likely pathogenic, 8 were variants of ion channel-related genes (GABRG2, HCN1, KCNB1, KCNT1, SCNIA, and SCN9A), 8 of mTOR genes (DEPDC5, TSC1, and TSC2), 3 of cell adhesion molecule/receptor-related genes (ADGRV1 and CNTNAP2), (EFHC1 and PRICKLE1) (Table 4) (Myers \& Mefford, 2015; Wang et al., 2017; GeneCards ${ }^{\circledR}$ ). Three genes (SCNIA, TSC1, and TSC2) were found to have a higher diagnostic yield of genetic testing, with each accounting for $15.6 \%(5 / 32)$ of the total yield. Five of two hundred and fortythree APEs (2.1\%) had two independent P/LPs simultaneously, the functional categories of 
274 the mTOR gene variants.

275

\section{Pathogenic potential of EAGs in AED responsiveness}

277

278

279

280

281

282

283

284

285

286

287

288

289

290

291

292

293

294

295

296

The diagnostic yield was $10.7 \%$ in the DS group and $15.6 \%$ in the DR group $(p>0.05)$. Six genes were commonly associated with both the DS and the DR group, including ADGRV1, DEPDC5, PRICKLE1, SCNIA, TSC1, and TSC2. Structural brain lesions were seen in 17 of the 32 APEs (53.1\%) with P/LPs, which are highly likely to have caused their epilepsies, whereas $63.2 \%$ of the DR group but $38.5 \%$ of the DS group had potentially causal lesions.

Two APEs with SCN1A p.Arg1575Cys were seizure-free with monotherapy with carbamazepine (CBZ) while three APEs with SCN1A p.Thr398Met or p.Val971Ile were resistant to drugs with various mechanisms of action, including CBZ. Four of five P/LPs of TSC2 were associated with drug-resistant epilepsy, while drug responsiveness differed even among patients with the same variant of TSC1. All three APEs with RELN variants were multi-drug resistant (Table 4).

\section{Genotype-phenotype correlation}

Thirty-one of the thirty-two APEs with P/LPs had focal epilepsies. Of the three APEs with the ADGRV1 p.His1859Arg variant, two were diagnosed with focal epilepsy and one with generalized epilepsy.

In 5 of the 12 APEs with ion channel-related gene variants, potentially disease-causative lesions were identified, including a tumor, focal cortical dysplasia (FCD), hippocampal scleroses (HS), and traumatic brain tissue loss. Two had a definite history of febrile seizures (FS) and one (JN168 in Table 4) had a history of what was considered to be an early infantile EE (i.e. seizure 
297

298

299

300

301

302

303

304

305

306

307

308

309

310

311

312

313

314

315

316

317

318

319

onset during infancy, autistic behaviors, mental retardation, and multi-drug resistant seizures).

Eight of ten APEs (80\%) with TSC1 or TSC2 variants but none of the three APEs with DEPDC5 variants had brain malformations including FCD, HS, or TS. Only one of ten APEs with TSC1 or TSC2 variants had clinical presentations fitting the diagnostic criteria of tuberous sclerosis complex (Samueli et al., 2015). In six of the eight APEs with malformations, the seizures were multi-drug resistant and the mean duration from seizure onset to genetic diagnosis was approximately 27.7 years. One of the thirteen APEs with P/LPs of mTOR genes had a history of FS (Table 4).

\section{Discussion}

\section{Possible causal genetic variants of non-familial epilepsy}

In the present study, we discovered possible causal genetic variants in $13.2 \%(32 / 243)$ of non-familial epilepsy cases. Insofar as non-familial focal epilepsy only and non-familial adulthood-onset epilepsy only were concerned, the diagnostic yields were $14.6 \%(31 / 213)$ and $14.7 \%(16 / 109)$, respectively. Although other study designs varied such that direct comparison to our study may not be suitable, there was a distinct tendency of higher genetic yields to associate with early childhood epilepsy with a distinct phenotype such as early onset DEEs, a positive history of familial epilepsy, or a generalized epilepsy (Lemke et al., 2012; Carvill et al., 2013; Kodera et al., 2013; Wang et al., 2014; Della Mina et al., 2015; Mercimek-Mahmutoglu et al., 2015; Hildebrand et al., 2016; Møller et al., 2016; Dunn et al., 2018; Ko et al., 2018; Rim et al., 2018; Lee et al., 2018). Given that the present study examined primarily non-familial focal 
320 epilepsies with heterogeneous phenotypes, of which almost half were adulthood-onset epilepsies,

321 and adopted WES for genetic testing that encompasses only a proportion of all mutations, the

322 genetic yields found in our study were beyond our expectation. This should be considered a

323 justification for physicians determining potentially causal genetic variants in non-familial APEs

324 that are frequently encountered in clinical practice.

325 Targeted gene panels have been most frequently used for genetic testing as they are rapid 326 and cost-efficient (Lemke et al., 2012). However, target genes must be limited to known

327 mutations at the time of diagnosis, thus posing a challenging task with regard to keeping pace

328 with newly identified genes after genetic testing, which often results in false-negative findings.

329 Advancements in sequencing technology continuously and rapidly extend the list of novel

330 epilepsy-causing genes and the cost of sequencing technology continues to drop. Therefore,

331 WES or even whole genome sequencing offers substantial advantages in identifying potential

332 causal epilepsy-related variants, particularly those of genetically undetermined non-familial

333 epilepsies with heterogeneous phenotypes because new hypotheses for identifying novel epilepsy

334 genes can be simply tested by reanalyzing previous WES or WGS data in silico.

335

336 Genotype-phenotype correlation

337 The mTOR genes including DEPDC5, TSC1, and TSC2 have been associated with focal

338 epilepsy, as was the case in our study in which the mTOR genes had the highest yield (13/32),

339 although the yield was relatively low in some previous studies (Lindy et al., 2018; Perucca et al.,

340 2017; Carvill et al., 2013). It is known that activating the mTOR pathway causes the

341 epileptogenicity of brain malformations, specifically FCD, TS, and HS (Liu et al., 2014), which

342 is supported by our finding that $80 \%$ of APEs with TSC1 or TSC2 variants had such 
343 malformations.

344 The ion channel-related genes are well-known to be the common genetic causes of early-

345

346

347

348

349

350

351

352

353

354

355

356

357

358

359

360

361

362

363

364

365 onset epilepsies such as early-onset DEEs or genetic focal or generalized epilepsies, and were frequently identified as the presumed causative genes of epilepsy in most of the corresponding pediatric studies (Lemke et al., 2012; Carvill et al., 2013; Kodera et al., 2013; Wang et al., 2014; Della Mina et al., 2015; Mercimek-Mahmutoglu et al., 2015; Hildebrand et al., 2016; Møller et al., 2016; Perucca et al., 2017; Dunn et al., 2018; Ko et al., 2018; Rim et al., 2018; Lee et al., 2018;). Ion channel-related genes had a higher yield (12/32) even in the present study, in which almost half of cases were adulthood-onset epilepsies. Given that 5 of 12 APEs with P/LPs of ion channel-related genes had adulthood-onset epilepsies, it seems plausible that these genes are implicated more frequently than expected in non-familial focal epilepsies in adulthood. While this needs to be functionally validated, it may widen our concept of the genetic spectrum of epilepsy in adulthood, which may in turn guide the development of adequate treatment options. $A D G R V 1$ haploinsufficiency may be an important contributor to the development of genetic epilepsies, particularly those with myoclonic seizures (Myers et al., 2018). In our study, three APEs with the ADGRV1 heterozygous variant (p.His1859Arg) had either focal or generalized epilepsy, which might be plausible if a focal myoclonic seizure was confused with a focal motor seizure, as is occasionally the case in outpatient clinics. CNTNAP2 has been associated with cortical dysplasia-focal epilepsy syndrome (CDFES; OMIN\#610042) or autosomal dominant epilepsy with auditory features (Pippucci et al., 2015). Although the original CDFES is an autosomal recessive trait, the APE (SU023 in Table 4) with the heterozygous CNTNAP2 p.Ile172Thr variant in our study exhibited the typical CDFES features of focal cortical dysplasia and focal epilepsy. The other APE with CNTNAP2 p.Arg1288Cys had non-lesional focal 
366 epilepsy without auditory aura. A compound heterozygosity test using CNVkit was negative in

367 these two cases. It is known that EFHC1 Arg294His is a genetic cause of childhood absence

368 epilepsy and juvenile myoclonus epilepsy (von Podewils et al., 2015). However, APEs with

369 EFHC1 Arg294Cys, an allelic variant of Arg294His, had acquired posttraumatic epilepsy in our

370 study. De novo heterozygous PRICKLE1 variants have been linked to congenital brain

371 malformations or myoclonic epilepsies (Bassuk \& Sherr, 2015; Todd \& Bassuk, 2018), while

372 two of three APEs with PRICKLE1 p.Ala541Ser variants in our study had non-lesional focal

373 epilepsy and the other had acquired postencephalitic epilepsy. Although RELN has been

374 associated with brain malformations and autosomal dominant lateral temporal lobe epilepsy, one

375 of two APEs with RELN p.Thr1904Met variants had hippocampal sclerosis, one of the main

376 pathological feature of mesial temporal lobe epilepsy, and the other had typical dermatological

377 and radiological features of TS but the genetic test for TSC1 or TSC2 was negative. Further study

378 is needed to elucidate whether RELN contributes to TS.

\section{Disease-modifying potential}

381

382

383

384

385

386

387

388
The higher yield of genetic testing for familial epilepsies or early-onset DEEs has been associated with an earlier seizure onset or severity of the epilepsy (Møller et al., 2016; Perucca et al., 2017). However, such correlations were not evident in our study. This inconsistency may highlight characteristics of the genetic contribution to non-familial epilepsies with a later age of onset or that are not so severe as to last until adulthood. Although most ion channel-related genes or mTOR genes have been associated with early-onset epilepsy syndromes with severe phenotypes such as Dravet's syndrome or intractable epilepsy with brain malformations that can lead to a grave outcome in early life, most APEs with P/LPs of ion channel-related genes or 
389

390

391

392

393

394

395

396

397

398

399

400

401

402

403

404

405

406

407

408

409

410

411

mTOR genes in our study experienced a later age of epilepsy onset or epilepsies that continued into adulthood. This suggests that these genes must somehow be linked to a disease-modifying mechanism that regulates the onset time or severity of the relevant epilepsy.

It is known that mTOR inhibitors such as rapamycin or everolimus have anti-epileptogenic effects rather than a simple seizure-suppression effect, as well as anti-tumor effects in TS (Franz \& Krueger, 2018). Interestingly, in our study, all APEs with two P/LPs simultaneously had an mTOR gene variant. Although it requires validation in future studies, this finding, together with the mTOR inhibitors' modulating effects on epileptogenesis and tumor growth in TS (Franz \& Krueger, 2018), suggests that mTOR genes are implicated in epileptogenesis or brain malformations (or both) as a key modulator of epistasis (gene-to-gene interaction). This could be supported by a recent report that $D E P D C 5$, as a single mTOR gene, is a key contributor to a broad spectrum of lesional and non-lesional epilepsies, with variable but highly consistent phenotypes (Baldassari et al., 2019). Furthermore, considering that most APEs with TSC1 or TSC2 variants in our study experienced brain malformations and multi-drug resistant epilepsy for approximately 30 years on average, the notion of mTOR inhibitors with disease-modifying effects is a reminder of the importance of early identification of mTOR gene variants in patients with epilepsy or other dermatological mimics of TS to treat or halt disease progression.

$$
\text { Many of the P/LPs identified in our study were associated with atypical phenotypes or }
$$
inheritance patterns that have not yet been reported in relation to their relevant epilepsies or epilepsy syndromes. This raises the possibility that the genetic basis of non-familial epilepsies, regardless of seizure onset time, differs from that of known familial epilepsies or pediatric DEEs. Given that five APEs with a mean seizure onset age of 44.2 years (range: $32-55$ years) in whom possible genetic causes were identified had definitely acquired etiologies prior to seizure onset, 
412 including traumatic brain tissue loss or encephalitis, it is plausible that one variant of the relevant

413 genes (SCN1A, TSC1, ADGRV1, EFHC1, and PRICKLE1) alone may not be sufficient to cause

414 the relevant epilepsies in the absence of acquired brain damage. This also reinforces the

415 implication of disease-modifying factors - whether they are genetic, environmental, or

416 something yet to be identified - in the pathogenesis of epilepsies that start in or last until

417 adulthood.

418

419

\section{Pathogenic potential of EAGs in epilepsy pharmacoresistance}

It is known that $S C N 1 A$ variants are associated with poor surgical outcomes and CBZ-

421

422

423

424

425

426

427

428

429

430

431

432

433

434 induced seizure aggravation (Franco \& Perucca, 2015; Skjei et al., 2015). In our study, the

treatment response to $\mathrm{CBZ}$ varied according to individual variants, suggesting that $S C N 1 A$ -

although this is inconclusive due to the small sample size. Nevertheless, the results of our study can be used to guide a trial to halt CBZ use in APEs with multi-drug resistance.

Unlike our expectation, the target hypothesis of epilepsy pharmacoresistance was not verified in our study. Instead, most APEs with P/LPs of neurodevelopment-associated epilepsy genes such as TSC2 or RELN, or with structural brain lesions, were multi-drug resistant. This suggests that pharmacoresistance in APEs may, at least in part, be linked to neural network rearrangement by structural lesions or potential somatic mutations in situ. An international collaboration of epilepsy studies could uncover these results.

The present study has several limitations. First, WES is not the best option for detecting copy number variants, large-sized indels, trinucleotide repeats, intronic alterations, intergenic variants, structural chromosomal rearrangements, or epigenetic modifications associated with 
435 epilepsy (Biesecker \& Green, 2014). This suggests that the diagnostic yield of our study may be 436 the minimum yield possible with WES for non-familial APEs. Second, although all identified

437 P/LPs are seemingly post-zygotic de novo mutations defined by the absence of family history of 438 epilepsy, the possibilities of unknown family histories, somatic mutation, genetic mosaicism, or 439 lower penetrance were not validated owing to limitations in DNA or tissue sampling. Third, 440 although the variants were selected via a customized stringent filtering process and classified as 441 pathogenic or likely pathogenic according to ACMG guidelines, the pathogenicity of each 442 variant should be confirmed in future studies. Fourth, this study selected target genes for analysis 443 from known epilepsy-related genes, which precludes the chance to identify novel epilepsy genes. 444 However, detecting mutations in known epilepsy genes in patients with an uncommon or 445 unspecific presentation of a seizure disorder may help reveal the true phenotypic spectrum of the 446 disorder (Lemke et al., 2012).

\section{Conclusions}

Our study possibly reveals causal genetic variants in $13.2 \%$ of non-familial patients with predominantly focal epilepsy in which mTOR genes and ion channel-related genes are most commonly associated. These potentially pathogenic variants, identified in the genes that have been associated with early-onset epilepsies with severe phenotypes, were also linked to epilepsies that start in or last until adulthood in this study, thereby suggesting the implication of one or more disease-modifying factors that regulate the onset time or severity of the disease during epileptogenesis. Neurodevelopment-associated epilepsy genes, such as TSC2 or RELN, or

456 structural brain lesions were more strongly associated with epilepsy pharmacoresistance. Our 
457 results highlight the importance of earlier identification of the genetic etiology of non-familial

458 epilepsies in adulthood, leading us to the best treatment option in terms of precision medicine 459 and to future neurobiological research for novel drug development.

460

461

462

463

464

465

466

467

468

469

470

471

472

473

Peer) reviewing PDF | (2019:06:38371:1:2:NEW 4 Oct 2019) 
474 Acknowledgements

475

476 We are grateful to the patients for their help and participation in the study. We thank Hee-

477 Joo Kim and Sun-Ok Lee for technical assistance. We would like to thank Editage

478 (www.editage.co.kr) for English language editing.

479

480

481

482

483

484

485

486

487

488

489

490

491

492

493

494

495

496

497

498

499

500

501

502

Peer) reviewing PDF | (2019:06:38371:1:2:NEW 4 Oct 2019) 
503

504

505

506

507

508

509

510

511

512

513

514

515

516

517

518

519

520

521

522

523

524

525

526

527

528

529

530

\section{References}

Baldassari S, Picard F, Verbeek NE, van Kempen M, Brilstra EH, Lesca G, Conti V, Guerrini R, Bisulli F, Licchetta L, Pippucci T, Tinuper P, Hirsch E, de Saint Martin A, Chelly J, Rudolf G, Chipaux M, Ferrand-Sorbets S, Dorfmüller G, Sisodiya S, Balestrini S, Schoeler N, Hernandez-Hernandez L, Krithika S, Oegema R, Hagebeuk E, Gunning B, Deckers C, Berghuis B, Wegner I, Niks E, Jansen FE, Braun K, de Jong D, Rubboli G, Talvik I, Sander V, Uldall P, Jacquemont ML, Nava C, Leguern E, Julia S, Gambardella A, d'Orsi G, Crichiutti G, Faivre L, Darmency V, Benova B, Krsek P, Biraben A, Lebre AS, Jennesson M, Sattar S, Marchal C, Nordli DR Jr, Lindstrom K, Striano P, Lomax LB, Kiss C, Bartolomei F, Lepine AF, Schoonjans AS, Stouffs K, Jansen A, Panagiotakaki E, Ricard-Mousnier B, Thevenon J, de Bellescize J, Catenoix H, Dorn T, Zenker M, Müller-Schlüter K, Brandt C, Krey I, Polster T, Wolff M, Balci M, Rostasy K, Achaz G, Zacher P, Becher T, Cloppenborg T, Yuskaitis CJ, Weckhuysen S, Poduri A, Lemke JR, Møller RS, Baulac S. (2019) The landscape of epilepsyrelated GATOR1 variants. Genet Med. 21:398-408.

Bassuk AG, Sherr EH. (2015) A de novo mutation in PRICKLE1 in fetal agenesis of the corpus callosum and polymicrogyria. J Neurogenet. 29:174-177.

Biesecker LG, Green RC. (2014) Diagnostic clinical genome and exomesequencing. N Engl J Med. 370:2418-2425.

Bisulli F, Tinuper P, Scudellaro E, Naldi I, Bagattin A, Avoni P, Michelucci R, Nobile C. (2004) A de novo LGI1mutation in sporadic partial epilepsy with auditory features. Ann Neurol. $56: 455-456$.

Carvill GL, Heavin SB, Yendle SC, McMahon JM, O'Roak BJ, Cook J, Khan A, Dorschner MO, Weaver M, Calvert S, Malone S, Wallace G, Stanley T, Bye AM, Bleasel A, Howell KB, Kivity S, Mackay MT, Rodriguez-Casero V, Webster R, Korczyn A, Afawi Z, Zelnick N, Lerman-Sagie T, Lev D, Møller RS, Gill D, Andrade DM, Freeman JL, Sadleir LG, Shendure J, Berkovic SF, Scheffer IE, Mefford HC. (2013) Targeted resequencing in epileptic encephalopathies identifies de novo mutations in CHD2 and SYNGAP1. Nat Genet. 45:825- 
830.

532 Claes L, Del-Favero J, Ceulemans B, Lagae L, Van Broeckhoven C. De Jonghe P. (2001) De

533 novo mutations in the sodium-channel gene SCN1A cause severe myoclonic epilepsy of 534 infancy. Am J Hum Genet. 68:1327-1332.

535

536

537

538

539

540

541

542

543

544

545

546

547

548

549

550

551

552

553

554

555

556

Della Mina E, Ciccone R, Brustia F, Bayindir B, Limongelli I, Vetro A, Iascone M, Pezzoli L, Bellazzi R, Perotti G, De Giorgis V, Lunghi S, Coppola G, Orcesi S, Merli P, Savasta S, Veggiotti P, Zuffardi O. (2015) Improving molecular diagnosis in epilepsy by a dedicated high-throughput sequencing platform. European Journal of Human Genetics. 23:354-362.

Dong C, Wei P, Jian X, Gibbs R, Boerwinkle E, Wang K, Liu X. (2015) Comparison and integration of deleteriousness prediction methods for nonsynonymous SNVs in whole exome sequencing studies. Hum Mol Genet. 24:2125-2137.

Dunn P, Albury CL, Maksemous N, Benton MC, Sutherland HG, Smith RA, Haupt LM and Griffiths LR. (2018) Next Generation Sequencing Methods for Diagnosis of Epilepsy Syndromes. Front. Genet. 9:20.

Fiest KM, Sauro KM, Wiebe S, Patten SB, Kwon C-S, Dykeman J, Pringsheim T, Lorenzetti DL, Jetté N. (2017) Prevalence and incidence of epilepsy: a systematic review and meta-analysis of international studies. Neurology. 88:296-303.

Fisher RS, Acevedo C, Arzimanoglou A, Bogacz A, Cross JH, Elger CE, Engel J Jr, Forsgren L, French JA, Glynn M, Hesdorffer DC, Lee BI, Mathern GW, Moshé SL, Perucca E, Scheffer IE, Tomson T, Watanabe M, Wiebe S. (2014) ILAE official report: a practical clinical definition of epilepsy. Epilepsia. 55:475-482.

Franco V, Perucca E. (2015) The pharmacogenomics of epilepsy. Expert Rev Neurother. $15: 1161-1170$.

Franz DN and Krueger DA. (2018) mTOR inhibitor therapy as a disease modifying therapy for tuberous sclerosis complex. Am J Med Genet C Semin Med Genet. 178:365-373.

GeneCards ${ }^{\circledR}$ Human Gene Database. https://www.genecards.org/ 
557 Hildebrand MS, Myers CT, Carvill GL, Regan BM, Damiano JA, Mullen SA, Newton MR, Nair

558 U, Gazina EV, Milligan CJ, Reid CA, Petrou S, Scheffer IE, Berkovic SF, Mefford HC. (2016)

559 A targeted resequencing gene panel for focal epilepsy. Neurology. 86:1605-1612.

560

561

562

563

564

565

566

567

568

569

570

571

572

573

574

575

576

577

578

579

580

581

582

Ko A, Youn SE, Kim SH, Lee JS, Kim S, Choi JR, Kim HD, Lee ST, Kang HC. (2018) Targeted gene panel and genotype-phenotype correlation in children with developmental and epileptic encephalopathy. Epilepsy Res. 141:48-55.

Kodera H, Kato M, Nord AS, Walsh T, Lee M, Yamanaka G, Tohyama J, Nakamura K, Nakagawa E, Ikeda T, Ben-Zeev B, Lev D, Lerman-Sagie T, Straussberg R, Tanabe S, Ueda K, Amamoto M, Ohta S, Nonoda Y, Nishiyama K, Tsurusaki Y, Nakashima M, Miyake N, Hayasaka K, King MC, Matsumoto N, Saitsu H. (2013) Targeted capture and sequencing for detection of mutations causing early onsetepileptic encephalopathy. Epilepsia. 54:1262-1269.

Kwan P, Arzimanoglou A, Berg AT, Brodie MJ, Allen Hauser W, Mathern G, Moshé SL, Perucca E, Wiebe S, French J. (2010) Definition of drug resistant epilepsy: consensus proposal by the ad hoc Task Force of the ILAE Commission on Therapeutic Strategies. Epilepsia. 51:1069-1077.

Lee CG, Lee J, Lee M. (2018) Multi-gene panel testing in Korean patients with common genetic generalized epilepsy syndromes. PLoS One.13:e0199321.

Lemke JR, Riesch E, Scheurenbrand T, Schubach M, Wilhelm C, Steiner I, Hansen J, Courage C, Gallati S, Bürki S, Strozzi S, Simonetti BG, Grunt S, Steinlin M, Alber M, Wolff M, Klopstock T, Prott EC, Lorenz R, Spaich C, Rona S, Lakshminarasimhan M, Kröll J, Dorn T, Krämer G, Synofzik M, Becker F, Weber YG, Lerche H, Böhm D, Biskup S. (2012) Targeted next generation sequencing as a diagnostic tool in epileptic disorders. Epilepsia. 53:13871398.

Lindy AS, Stosser MB, Butler E, Downtain-Pickersgill C, Shanmugham A, Retterer K, Brandt T, Richard G, McKnight DA.(2018) Diagnostic outcomes for genetic testing of 70 genes in 8565 patients with epilepsy and neurodevelopmental disorders. Epilepsia. 59:1062-1071. 
583

584

585

586

587

588

589

590

591

592

593

594

595

596

597

598

599

600

601

602

603

604

605

606

607

608

609

Liu J, Reeves C, Michalak Z, Coppola A, Diehl B, Sisodiya SM, Thom M. (2014) Evidence for mTOR pathway activation in a spectrum of epilepsy-associated pathologies. Acta Neuropathol Commun. 2:71

Liu X, Wu C, Li C, Boerwinkle1 E. (2016) dbNSFP v3.0: A One-Stop Database of Functional Predictions and Annotations for Human Nonsynonymous and Splice-Site SNVs. Hum Mutat. $37: 235-241$.

Mercimek-Mahmutoglu S, Patel J, Cordeiro D, Hewson S, Callen D, Donner EJ, Hahn CD, Kannu P, Kobayashi J, Minassian BA, Moharir M, Siriwardena K, Weiss SK, Weksberg R, Snead 3rd OC. (2015) Diagnostic yield of genetic testing in epileptic encephalopathy in childhood. Epilepsia 56, 707-716.

Milligan CJ, Li M, Gazina EV, Heron SE, Nair U, Trager C, Reid CA, Venkat A, Younkin DP, Dlugos DJ, Petrovski S, Goldstein DB, Dibbens LM, Scheffer IE, Berkovic SF, Petrou S. (2014) KCNT1 gain of function in 2 epilepsy phenotypes is reversed by quinidine. Ann Neurol. 75:581-590.

Møller RS, Larsen LH, Johannesen KM, Talvik I, Talvik T, Vaher U, Miranda MJ, Farooq M, Nielsen JE, Svendsen LL, Kjelgaard DB, Linnet KM, Hao Q, Uldall P, Frangu M, Tommerup N, Baig SM, Abdullah U, Born AP, Gellert P, Nikanorova M, Olofsson K, Jepsen B, Marjanovic D, Al-Zehhawi LI, Peñalva SJ, Krag-Olsen B, Brusgaard K, Hjalgrim H, Rubboli G, Pal DK, Dahl HA. (2016) Gene Panel Testing in Epileptic Encephalopathies and Familial Epilepsies. Mol Syndromol. 7:210-219.

Myers CT and Mefford HC. (2015) Advancing epilepsy genetics in the genomic era. Genome Medicine. 7:91.

Myers KA, Nasioulas S, Boys A, McMahon JM, Slater H, Lockhart P, Sart DD, Scheffer IE. (2018) ADGRV1 is implicated in myoclonic epilepsy. Epilepsia. 59:381-388.

Nava C, Dalle C, Rastetter A, Striano P, de Kovel CG, Nabbout R, Cancès C, Ville D, Brilstra EH, Gobbi G, Raffo E, Bouteiller D, Marie Y, Trouillard O, Robbiano A, Keren B, Agher D, Roze E, Lesage S, Nicolas A, Brice A, Baulac M, Vogt C, El Hajj N, Schneider E, Suls A, 
610

611

612

613

614

615

616

617

618

619

620

621

622

623

624

625

626

627

628

629

630

631

632

633

634

635

636

Weckhuysen S, Gormley P, Lehesjoki AE, De Jonghe P, Helbig I, Baulac S, Zara F, Koeleman BP; EuroEPINOMICS RES Consortium, Haaf T, LeGuern E, Depienne C. (2014)

De novo mutations in HCN1 cause early infantile epileptic encephalopathy. Nat Genet.46:640-645.

Perucca P, Scheffer IE, Harvey AS, James PA, Lunke S, Thorne N, Gaff C, Regan BM, Damiano JA, Hildebrand MS, Berkovic SF, O'Brien TJ, Kwan P. (2017) Real-world utility of whole exome sequencing with targeted gene analysis for focal epilepsy. Epilepsy Res. 131:1-8.

Phillips HA, Marini C, Scheffer IE, Sutherland GR, Mulley JC, Berkovic SF. (2000) A de novo mutation in sporadic nocturnal frontal lobe epilepsy. Ann Neurol. 48:264-267.

Pierson TM, Yuan H, Marsh ED, Fuentes-Fajardo K, Adams DR, Markello T, Golas G, Simeonov DR, Holloman C, Tankovic A, Karamchandani MM, Schreiber JM, Mullikin JC; PhD for the NISC Comparative Sequencing Program, Tifft CJ, Toro C, Boerkoel CF, Traynelis SF, Gahl WA. (2014) GRIN2A mutation and early-onset epileptic encephalopathy: personalized therapy with memantine. Ann Clin Transl Neurol. 1:190-198.

Pippucci T, Licchetta L, Baldassari S, Palombo F, Menghi V, D'Aurizio R, Leta C, Stipa C, Boero G, d'Orsi G, Magi A, Scheffer I, Seri M, Tinuper P, Bisulli F. (2015) Epilepsy with auditory features: A heterogeneous clinico-molecular disease. Neurol Genet. 1:e5.

Richards S, Aziz N, Bale S, Bick D, Das S, Gastier-Foster J, Grody WW, Hegde M, Lyon E, Spector E, Voelkerding K, Rehm HL. (2015) ACMG Laboratory Quality Assurance Committee. Standards and guidelines for the interpretation of sequence variants: a joint consensus recommendation of the American College of Medical Genetics and Genomics and the Association for Molecular Pathology. Genet Med. 17:405-424.

Rim JH, Kim SH, Hwang IS, Kwon SS, Kim J, Kim HW, Cho MJ, Ko A, Youn SE, Kim J, Lee YM, Chung HJ, Lee JS, Kim HD, Choi JR, Lee ST, Kang HC. (2018) Efficient strategy for the molecular diagnosis of intractable early-onset epilepsy using targeted gene sequencing. BMC Med Genomics. 11:6.

Skjei KL, Church EW, Harding BN, Santi M, Holland-Bouley KD, Clancy RR, Porter BE, Heuer 
637

638

639

640

641

642

643

644

645

646

647

648

649

650

651

652

653

654

655

656

657

GG, Marsh ED. (2015) Clinical and histopathological outcomes in patients with SCN1A mutations undergoing surgery for epilepsy. J Neurosurg Pediatr. 16:668-674.

Samueli S ${ }^{1}$, Abraham K, Dressler A, Groeppel G, Jonak C, Muehlebner A, Prayer D, Reitner A, Feucht M; Pädiatrisches TSC-Zentrum Wien. (2015) Tuberous Sclerosis Complex: new criteria for diagnostic work-up and management. Wien Klin Wochenschr. 127:619-630.

Talevich, E., Shain, A.H., Botton, T., \& Bastian, B.C. (2016). CNVkit: Genome-wide copy number detection and visualization from targeted sequencing. PLOS Computational Biology 12(4):e1004873.

Tang F, Hartz AMS and Bauer B (2017) Drug-Resistant Epilepsy: Multiple Hypotheses, Few Answers. Front. Neurol. 8:301.

Thomas RH \& Berkovic SF. (2014) The hidden genetics of epilepsy-a clinically important new paradigm. Nat. Rev. Neurol. 10: 283-292.

Todd BP, Bassuk AG. (2018) A de novo mutation in PRICKLE1 associated with myoclonic epilepsy and autism spectrum disorder. J Neurogenet. 32:313-315.

von Podewils F, Kowoll V, Schroeder W, Geithner J, Wang ZI, Gaida B, Bombach P, Kessler C, Felbor U, Runge U. (2015) Predictive value of EFHC1 variants for the long-term seizure outcome in juvenile myoclonic epilepsy. Epilepsy Behav. 44:61-66.

Wang J, Gotway G, Pascual JM, Park JY. (2014) Diagnostic Yield of Clinical Next

Generation Sequencing Panels for Epilepsy. JAMA Neurol. 71:650-651.

Wang J, Lin ZJ, Liu L, Xu HQ, Shi YW, Yi YH, He N, Liao WP. (2017) Epilepsy-associated genes. Seizure. 44:11-20.

Peer) reviewing PDF | (2019:06:38371:1:2:NEW 4 Oct 2019) 


\section{Figure 1}

\section{Workflow of variants filtering process.}

WES; whole exome sequencing, SNPs; single nucleotide polymorphisms, ACMG; American College of Medical Genetics and Genomics. 


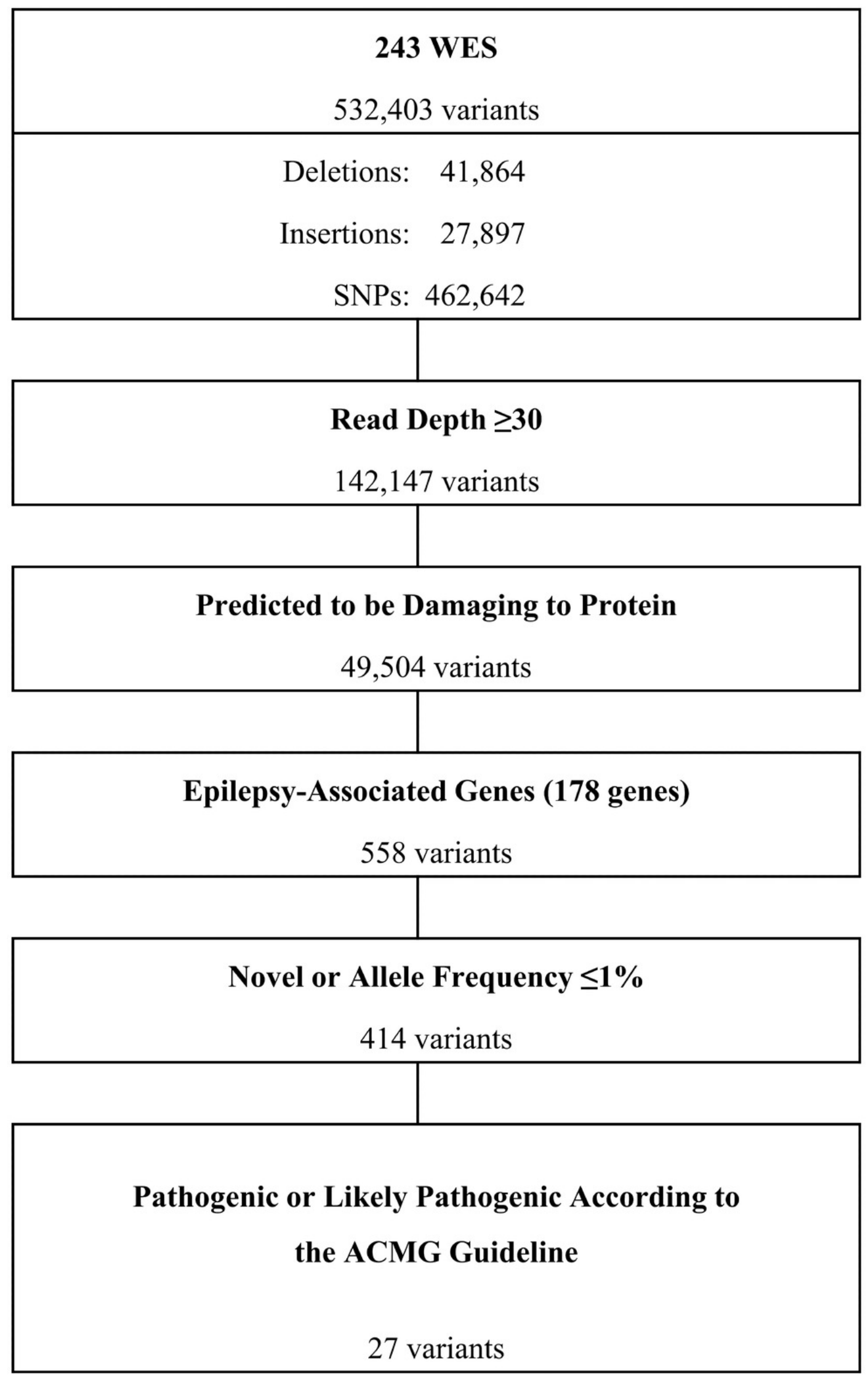


Table $\mathbf{1}$ (on next page)

Epilepsy Associated Genes 


\section{Table 1. Epilepsy Associated Genes.}

2

3 Epilepsy Genes $A A R S, A D R A 2 B, A D S L, A L D H 7 A 1$ ALG13, ARV1, ATP6AP2, CACNA1A, CACNA1H,

4 CACNB4, CASR, CDKL5, CERS1, CHD2, CHRNA2, CHRNA4, CHRNB2, CLCN2, CLN3, CLN5, CLN6,

5 CLN8, CNTN2, CPA6, CSTB, CTSD, DEPDC5, DNM1, DOCK7, EEF1A2, EFHC1, EPM2A, FGF12,

6 FOXG1, FRRSIL, GABRA1, GABRB1, GABRB3, GABRD, GABRG2, GAL, GAMT, GATM, GNAO1,

7 GOSR2, GPR98, GRIN2A, GRIN2B, GRIN2D, GUF1, HCN1, ITPA, KCNA2, KCNB1, KCNC1, KCNMA1,

8 KCNQ2, KCNQ3, KCNT1, KCTD7, LGI1, LMNB2, MFSD8, NECAP1, NHLRC1, NPRL2, NPRL3,

9 NRXN1, PCDH19, PLCB1, PNPO, POLG, PPT1, PRDM8, PRICKLE1, PRIMA1, PRRT2, SCARB2, SCN1A, SCN1B, SCN2A, SCN8A, SCN9A, SIK1, SLC12A5, SLC13A5, SLC1A2, SLC25A12, SLC25A22, SLC2A1, SLC6A1, SLC9A6, SPTAN1, ST3GAL3, ST3GAL5, STX1B, STXBP1, SZT2, TBC1D24, TCF4, TPP1, UBA5, UBE3A, WWOX, ZEB2

Neurodevelopment-associated Epilepsy Genes $A N K L E 2, A M P D 2, A R F G E F 2$, ARX, ASPM, ATN1, CASK, CCDC88C, CDK5, CENPE, CENPJ, CLP1, CNTNAP2, COL4A2, DCX, DIAPH1, EMX2, ERMARD, EXOSC3, FIG4, FLNA, GPR56, HERC1, IER3IP1, KATNB1, KIF11, KIF2A, KIF5C, LAMB1, LAMC3, MED17, MFSD2A, MPDZ, NDE1, NSDHL, OCLN, OPHN1, PAFAH1B1, PCLO, PIK3R2, PLEKHG2, PNKP, PPP1R15B, PTCH1, QARS, RELN, RTTN, SASS6, EPSECS, SLC12A6, SLC20A2, SNIP1, SPATA5, SRPX2, STAMBP, STRADA, SYN1, TRMT10A, TSC1, TSC2, TSEN15, TSEN2, TSEN54, TUBA1A, TUBA8, TUBB2A, TUBB2B,TUBB3, TUBG1, VPS53, WDR62, WDR73, XPR1 
Table 2 (on next page)

Characteristics of the study participants 
1 Table 2. Characteristics of the study participants

\begin{tabular}{|c|c|c|c|}
\hline & $\begin{array}{c}\text { Drug-responsive } \\
\quad(\mathrm{n}=121)\end{array}$ & $\begin{array}{c}\text { Drug-resistant } \\
\quad(\mathrm{n}=122)\end{array}$ & $p$-value \\
\hline \multicolumn{4}{|l|}{ Age (years) } \\
\hline at recruitment & $39.3 \pm 15.1$ (range, $20-84$ ) & $39.9 \pm 11.3$ (range, $20-68$ ) & 0.706 \\
\hline at seizure onset & $25.4 \pm 15.2($ range, $0-68)$ & $15.9 \pm 10.1$ (range, $0-45)$ & $<0.001$ \\
\hline Gender (male) & $65(53.7 \%)$ & $64(52.5 \%)$ & 0.898 \\
\hline \multicolumn{4}{|c|}{ Epilepsy classification } \\
\hline Generalized & $19(15.7 \%)$ & $4(3.3 \%)$ & \\
\hline Focal & $95(78.5 \%)$ & $118(96.7 \%)$ & $<0.001$ \\
\hline Unknown & $7(5.8 \%)$ & $0 \quad(0 \%)$ & \\
\hline
\end{tabular}

2 


\section{Table 3 (on next page)}

Pathogenic or Likely Pathogenic Variants According to the ACMG Guideline 
Table 3. Pathogenic or Likely Pathogenic Variants According to the ACMG Guideline.

\begin{tabular}{|c|c|c|c|c|c|c|c|}
\hline Gene & Chr. & Position & HGVS.p & OR & $95 \% \mathrm{CI}$ & ACMG Criteria ${ }^{19}$ & Interpretation \\
\hline$A D G R V 1$ & $\operatorname{chr} 5$ & $89,977,183$ & p.His1859Arg & 11.7 & $3.6-37.6$ & PS4, PM6, PP3, PP5 & Likely pathogenic \\
\hline CHRNA4 & $\operatorname{chr} 20$ & $61,981,730$ & p.Arg345Cys & NA & NA & $\begin{array}{l}\text { PS1, PS3, PM2, PM6, } \\
\text { PP3 }\end{array}$ & Pathogenic \\
\hline \multirow[t]{2}{*}{ CNTNAP2 } & $\operatorname{chr} 7$ & $146,741,111$ & p.Ile172Thr & 35.7 & $4.3-290.5$ & PS4, PM6, PP3, PP5 & Likely pathogenic \\
\hline & $\operatorname{chr} 7$ & $148,112,574$ & p.Arg1288Cys & 83.3 & 8.6- 802.2 & PS4, PM6, PP3, PP5 & Likely pathogenic \\
\hline \multirow[t]{2}{*}{$D E P D C 5$} & $\operatorname{chr} 22$ & $32,215,100$ & p.Arg587* & NA & NA & $\begin{array}{l}\text { PVS1, PS3, PM2, PM6, } \\
\text { PP3 }\end{array}$ & Pathogenic \\
\hline & $\operatorname{chr} 22$ & $32,242,890$ & p.Pro1031His & 7.0 & $1.7-28.7$ & PS4, PM6, PP3 & Likely pathogenic \\
\hline EFHCl & chr6 & $52,319,049$ & p.Arg294Cys & 125.2 & $11.3-1382.9$ & PS4, PM5, PP3, PP5 & Likely pathogenic \\
\hline$G A B R G 2$ & $\operatorname{chr} 5$ & $161,495,029$ & p.Ser8Arg & 250.6 & $35.2-1782.6$ & PS4. PM6, PP3, PP5 & Likely pathogenic \\
\hline HCN1 & $\operatorname{chr} 5$ & $45,695,898$ & p.Ser100Ala & 235.5 & $14.7-3770.7$ & PS4, PM5, PM6, PP3 & Likely pathogenic \\
\hline$K C N B 1$ & $\operatorname{chr} 20$ & $47,990,709$ & p.Ile463Thr & 14.7 & $1.9-110.8$ & PS4, PM6, PP3 & Likely pathogenic \\
\hline KCNT1 & $\operatorname{chr} 9$ & $138,670,613$ & p.Glu892Lys & 24.9 & $3.1-194.6$ & PS4, PM6, PP3, PP5 & Likely pathogenic \\
\hline PRICKLE1 & $\operatorname{chr} 12$ & $42,858,215$ & p.Ala541Ser & 376.9 & $62.8-2260.6$ & PS4, PM6, PP3, PP5 & Likely pathogenic \\
\hline \multirow[t]{2}{*}{$R E L N$} & $\operatorname{chr} 7$ & $103,197,510$ & p.Thr1904Met & 23.6 & $5.5-100.9$ & PS4, PM6, PP3, PP5 & Likely pathogenic \\
\hline & $\operatorname{chr} 7$ & $103,276,733$ & p.Lys751Thr & 9.6 & $1.3-71.1$ & PS4, PM6, PP3, PP5 & Likely pathogenic \\
\hline \multirow[t]{3}{*}{ SCN1A } & $\operatorname{chr} 2$ & $166,850,785$ & p.Arg1575Cys & 55.3 & $11.9-256.8$ & PS4, PM6, PP3, PP5 & Likely pathogenic \\
\hline & $\operatorname{chr} 2$ & $166,903,464$ & p.Thr398Met & 250.3 & $15.6-4007.8$ & PS4, PM6, PP3 & Likely pathogenic \\
\hline & $\operatorname{chr} 2$ & $166,894,321$ & p.Val971Ile & 55.3 & $11.9-256.7$ & PS4, PM6, PP3, PP5 & Likely pathogenic \\
\hline SCN9A & $\operatorname{chr} 2$ & $167,141,015$ & p.Asn641Ser & 123.3 & $11.2-1362.3$ & PS4, PM5, PM6, PP3 & Likely pathogenic \\
\hline \multirow[t]{3}{*}{ TSC1 } & $\operatorname{chr} 9$ & $135,771,689$ & p.Pro1143Leu & 83.4 & $8.7-803.3$ & PS4, PM6, PP3, PP5 & Likely pathogenic \\
\hline & $\operatorname{chr} 9$ & $135,772,927$ & p.Thr899Ser & 41.8 & $9.3-187.3$ & PS4, PM6, PP3, PP5 & Likely pathogenic \\
\hline & $\operatorname{chr} 9$ & $135,776,993$ & p.Ser829Arg & 62.4 & $13.2-294.6$ & PS4, PM6, PP3, PP5 & Likely pathogenic \\
\hline \multirow[t]{5}{*}{$T S C 2$} & $\operatorname{chr} 16$ & $2,134,649$ & p.Glu1476Gln & 62.1 & $6.9-556.7$ & $\begin{array}{l}\text { PS4, PM5, PM6, PP3, } \\
\text { PP5 }\end{array}$ & Pathogenic \\
\hline & $\operatorname{chr} 16$ & $2,135,247$ & p.Arg1529Gln & 13.3 & $1.8-100.2$ & PS4, PM6, PP3, PP5 & Likely pathogenic \\
\hline & $\operatorname{chr} 16$ & $2,127,648$ & p.Val963Met & 41.7 & $5.0-347.2$ & PS4, PM6, PP3, PP5 & Likely pathogenic \\
\hline & $\operatorname{chr} 16$ & $2,129,146$ & p.Leu1027Pro & NA & NA & PM2, PM6, PP3, PP5 & Likely pathogenic \\
\hline & $\operatorname{chr} 16$ & $2,134,692$ & p.Glu1490Gly & 14.5 & $1.9-108.7$ & PS4, PM6, PP3, PP5 & Likely pathogenic \\
\hline
\end{tabular}

1 ACMG; American College of Medical Genetics and Genomics, Chr; chromosome, HGCV.p; Human

2 Genome Variation Society nomenclature for protein, OR; odds ratio, CI; confidence interval, NA;

3 not available. 
Table 4 (on next page)

Presumed disease-causative genes of non-familial epilepsies 
Table 4. Presumed disease-causative genes of non-familial epilepsies

\begin{tabular}{|c|c|c|c|c|c|c|c|}
\hline \multicolumn{2}{|c|}{$P / L P$ variants $\uparrow$} & Pt_ID & $\begin{array}{l}\text { Sex/Age*, } \\
\text { years }\end{array}$ & $\begin{array}{c}\text { Drug } \\
\text { response }\end{array}$ & $\begin{array}{l}\text { Febrile } \\
\text { seizure }\end{array}$ & $\begin{array}{c}\text { Epilepsy } \\
\text { classification }\end{array}$ & Etiology \\
\hline \multicolumn{8}{|c|}{ ION CHANNEL-RELATED GENES } \\
\hline CHRNA4 & p.Arg345Cys & DK085 & $\mathrm{M} / 26(12)$ & DS & $\mathrm{N}$ & Focal & $\begin{array}{l}\text { Non- } \\
\text { lesional }\end{array}$ \\
\hline \multirow[t]{2}{*}{ GABRG2 } & p.Ser8Arg & JN086 & $\mathrm{M} / 22(4)$ & DR & $\mathrm{N}$ & Focal & Tumor \\
\hline & & JN167 & M/68 (10) & DR & $\mathrm{Y}$ & Focal & $\begin{array}{l}\text { Non- } \\
\text { lesional }\end{array}$ \\
\hline HCN1 & p.Ser100Ala & SC009 & $\mathrm{M} / 24(15)$ & DS & $\mathrm{N}$ & Focal & $\begin{array}{l}\text { Non- } \\
\text { lesional }\end{array}$ \\
\hline KCNB1 & p.Ile463Thr & JN134 & $\mathrm{F} / 52(29)$ & DS & $\mathrm{Y}$ & Focal & FCD \\
\hline KCNT1 & p.Glu892Lys & SU059 & $\mathrm{M} / 25(20)$ & DR & $\mathrm{N}$ & Focal & $\begin{array}{c}\text { Non- } \\
\text { lesional }\end{array}$ \\
\hline \multirow[t]{5}{*}{$S C N 1 A$} & p.Thr398Met & JN129 & $\mathrm{F} / 43(29)$ & DR & $\mathrm{N}$ & Focal & HS \\
\hline & p.Val971Ile & JN168 & $\mathrm{M} / 30(1)$ & DR & $\mathrm{N}$ & Focal & $\begin{array}{l}\text { Non- } \\
\text { lesional }\end{array}$ \\
\hline & & KG012 & $\mathrm{M} / 43$ (38) & DR & $\mathrm{N}$ & Focal & Trauma \\
\hline & p.Arg1575Cys & JN046 & $\mathrm{F} / 54(16)$ & DS & $\mathrm{N}$ & Focal & $\begin{array}{l}\text { Non- } \\
\text { lesional }\end{array}$ \\
\hline & & JN166 & $\mathrm{F} / 43(29)$ & DS & $\mathrm{N}$ & Focal & $\begin{array}{l}\text { Non- } \\
\text { lesional }\end{array}$ \\
\hline SCN9A & p.Asn641Ser & DK098 & $\mathrm{F} / 35(12)$ & DR & NA & Focal & HS \\
\hline \multicolumn{8}{|c|}{ mTOR PATHWAY-RELATED GENES } \\
\hline \multirow[t]{3}{*}{$D E P D C 5$} & p.Arg587* & DK023 & $\mathrm{F} / 26(19)$ & DS & $\mathrm{N}$ & Focal & $\begin{array}{l}\text { Non- } \\
\text { lesional }\end{array}$ \\
\hline & p.Pro1031His & SU059 & $\mathrm{M} / 25(20)$ & DR & $\mathrm{N}$ & Focal & $\begin{array}{l}\text { Non- } \\
\text { lesional }\end{array}$ \\
\hline & & JN114 & $\mathrm{M} / 38(11)$ & DS & $\mathrm{N}$ & Focal & $\begin{array}{l}\text { Non- } \\
\text { lesional }\end{array}$ \\
\hline \multirow[t]{5}{*}{ TSC1 } & p.Ser829Arg & SU036 & $\mathrm{M} / 40$ (1) & DR & $\mathrm{N}$ & Focal & FCD \\
\hline & & КH015 & $\mathrm{F} / 45(37)$ & DS & $\mathrm{N}$ & Focal & HS \\
\hline & p.Thr899Ser & SU023 & $\mathrm{M} / 33(21)$ & DR & $\mathrm{N}$ & Focal & FCD \\
\hline & & JN036 & $\mathrm{M} / 51(41)$ & DS & $\mathrm{Y}$ & Focal & Trauma \\
\hline & p.Pro1143Leu & JN224 & $\mathrm{F} / 65(55)$ & DS & $\mathrm{N}$ & Focal & Encephalitis \\
\hline \multirow[t]{5}{*}{$T S C 2$} & p.Val963Met & KH016 & F/42 (34) & DR & $\mathrm{N}$ & Focal & HS \\
\hline & p.Leu1027Pro & JN056 & M/37 (7) & DR & $\mathrm{N}$ & Focal & TS \\
\hline & p.Glu1476GIn & JN051 & M/49 (28) & DR & $\mathrm{N}$ & Focal & HS \\
\hline & p.Glu1490Gly & EW001 & F/64 (8) & DR & $\mathrm{N}$ & Focal & HS \\
\hline & p.Arg1529Gln & JN006 & $\mathrm{F} / 31(18)$ & DS & $\mathrm{N}$ & Focal & $\begin{array}{l}\text { Non- } \\
\text { lesional }\end{array}$ \\
\hline \multicolumn{8}{|c|}{ ADHESION MOLECULE/RECEPTOR-RELATED GENES } \\
\hline \multirow[t]{2}{*}{$A D G R V 1$} & p.His1859Arg & JN036 & $\mathrm{M} / 51(41)$ & DS & $\mathrm{Y}$ & Focal & Trauma \\
\hline & & JN023 & $\mathrm{F} / 25(5)$ & DR & $\mathrm{Y}$ & Focal & HS \\
\hline
\end{tabular}




$\begin{array}{llllllcc} & & \text { DK066 } & \text { F56 (46) } & \text { DS } & \text { N } & \text { Generalized } & \begin{array}{c}\text { Non- } \\ \text { lesional }\end{array} \\ \text { CNTNAP2 } & \text { p.Ile172Thr } & \text { SU023 } & \text { M/33(21) } & \text { DR } & \text { N } & \text { Focal } & \text { FCD } \\ & \text { p.Arg1288Cys } & \text { JN041 } & \text { M/38(17) } & \text { DR } & \text { N } & \text { Focal } & \begin{array}{c}\text { Non- } \\ \text { lesional }\end{array}\end{array}$

SIGNAL TRANSDUCTION-RELATED GENES

$\begin{array}{lllllllc}\text { EFHC1 } & \text { p.Arg294Cys } & \text { JN172 } & \text { M/36(32) } & \text { DS } & \text { Y } & \text { Focal } & \text { Trauma } \\ \text { PRICKLE1 } & \text { p.Ala541Ser } & \text { JN072 } & \text { M/60(33) } & \text { DR } & \text { Y } & \text { Focal } & \begin{array}{c}\text { Non- } \\ \text { lesional }\end{array} \\ & & \text { JN224 } & \text { F/65(55) } & \text { DS } & \text { N } & \text { Focal } & \begin{array}{c}\text { Encephalitis } \\ \text { Non- } \\ \text { lesional }\end{array}\end{array}$

EXTRACELLULAR MATRIX-RELATED GENES

\begin{tabular}{cccccccc} 
RELN & p.Lys751Thr & SU018 & F/44 (7) & DR & N & Focal & $\begin{array}{c}\text { Non- } \\
\text { lesional }\end{array}$ \\
& p.Thr1904Met & DK021 & F/44 (25) & DR & N & Focal & HS \\
& JN056 & M/37 (7) & DR & N & Focal & TS \\
\hline
\end{tabular}

$\dagger$; Bold denotes variants classified as pathogenic, + ; Bold denotes participant with two P/LPs, *;

Age at recruitment (at seizure onset), Abbreviations: DR; drug refractory group, DS; drug responsive group, FCD; focal cortical dysplasia, HS; hippocampal sclerosis, NA; not available, P/LP; pathogenic/likely pathogenic variant, TS; tuberous sclerosis, mTOR; mammalian target of rapamycin. 